\title{
Integrating Emotional Intelligence, Political Skill, and Transformational Leadership in Construction
}

\author{
Sunindijo, R.Y.1
}

\begin{abstract}
Much research has been conducted to demonstrate the roles of emotional intelligence, political skill, and transformational leadership in the organisational context. However, there is a lack of research that investigates the relationships between the three, particularly in the construction project environment, thus this research attempts to fill this gap. It was hypothesised that emotional intelligence serves as the foundation of these relationships, whilst political skill is the mediator and transformational leadership is the output. Questionnaire survey was used to collect data from three large construction organisations in Australia where 273 valid responses were received. Data were analysed using structural equation modelling method to test the theoretical model. The finding of this research advances theoretical understanding by showing the relationships between emotional intelligence, political skill, and transformational leadership. Practically, it helps construction organisations strategise in recruiting and developing their project personnel.
\end{abstract}

Keywords: Construction, emotional intelligence, political skill, project personnel, transformational leadership.

\section{Introduction}

Emotional intelligence, political skill, and transformational leadership are considered as essential capabilities to be successful at work. Emotional intelligence is "the capacity for recognising our own feelings and those of others, for motivating ourselves, and for managing emotions well in ourselves and in our relationships". It has been suggested that emotional intelligence is twice as important as IQ (intelligence quotient) and expertise in contributing to excellent and effective performance [1]. The significance of emotional intelligence is evident by its inclusion into some organisation development programs and business school curriculums [2]. In the construction project environment, emotional intelligence generates delegating, open communication, and proactive behaviour from project managers and engineers [3]. In addition, project leaders with high emotional intelligence have a tendency to promote harmony and pursue a win-win solution during conflict situations [4].

The second research variable, i.e., political skill, is "the ability to understand others at work and to use that knowledge to influence others to act in ways that enhance one's personal or organisational objectives" [5]. Traditionally, organisations adopted a bureaucratic style with a tall hierarchical structure and a formalised chain of command.

${ }^{1}$ Construction Management and Property, Faculty of the Built Environment, University of New South Wales, Sydney, AUSTRALIA. Email: r.sunindijo@unsw.edu.au
Nowadays, however, the nature of organisations has become more social, thus people are not considered to be good at their jobs if they are not experts at working with, and influencing others [5-8]. Politics has become an integral part of every organisation where people interact with each other to resolve conflicts, share limited amounts of resources, and gain greater power [9]. It is impossible to avoid political environments that exist within organisations because they have become an essential part of organisational life and career success. As a result, political skill has become crucial for treading safely on the political webs of organisations [10].

Finally, applying transformational leadership is considered effective to stimulate and inspire followers to go beyond their own self-interest to achieve extraordinary outcomes for the good of the organisation. Transformational leaders pay attention to the concerns and developmental needs of individual followers. They also help followers to look at old problems in new ways and are able to inspire followers to put in extra effort to achieve group goals [11]. Research has indicated that transformational leadership is an effective leadership style because it produces levels of employees' effort and performance that go beyond what would occur with the common transactional approach which uses a system of reward and punishment to motivate employees [12]. A study found that project managers who exercise transformational leadership enjoy greater success than their counterparts. The study concluded that a project manager must become a strong transformational role model and use a relationship-oriented approach towards his or her project team to achieve project success [13]. 
Much research has been conducted to demonstrate the role of emotional intelligence, political skill, and transformational leadership. However, there is a further need to integrate these three capabilities and understand how they influence one another. This understanding is necessary to design effective human resource development strategies for project personnel in the construction industry. Furthermore, the finding will enrich the human resource management body of knowledge in the construction project environment.

\section{Theoretical Model and Hypotheses}

There are three variables in this research, i.e., emotional intelligence, political skill, and transformational leadership. Emotional intelligence consists of four dimensions, namely, self-awareness, selfmanagement, social-awareness, and relationship management. First, self-awareness means to know oneself feeling at the moment and use it in decision making. A person high in self-awareness is aware of his or her strengths and weaknesses, open to feedback, and willing to learn from past experiences. Second, self-management is the ability to regulate distressing effects, such as anxiety and anger, and to restrain emotional impulsivity; thus a person will be able to hold in mind the positive feelings that will come when he or she achieves goals and inhibits the negative feelings. Additionally, a person high in selfmanagement is often able to boost motivation. Third, social-awareness enables a person to recognise other people's feelings. A person with high social-awareness has an ability to read nonverbal cues for emotional currents from others. This is particularly critical for job performance when the focus is on interactions with people. Lastly, relationship management is the ability to attune oneself to and influence the emotions of others [14]. In essence, relationship management enables a person to use awareness of own emotions and the emotions of others to manage interactions successfully [15].

Political skill also has four dimensions, namely, social astuteness, interpersonal influence, networking ability, and apparent sincerity. First, people with high social astuteness are attuned to diverse social situations, thus they are experts in social interacttions. They possess high self-awareness, but also sensitive to others and understand the behaviour of others, thus they are considered as ingenious and clever in dealing with others. Socially astute people show an accurate understanding of social situations and interpersonal interactions that take place in social settings. The second dimension, interpersonal influence, is characterised by inconspicuous and convincing personal style that exerts a strong influence to other people. People with high interpersonal influence are flexible. They can appropriately adapt their behaviour to each situation to elicit the desired responses from others. The third dimension is networking ability or the ability to develop and use diverse networks of people. People included in the networks are considered to hold valuable and necessary assets for attaining successful personal and organisational goals. People with high networking ability are often expert negotiators, deal makers, and at ease with conflict management. They easily develop rapport as well as essential alliances. The fourth dimension is apparent sincerity, which creates the perception of high levels of integrity, authenticity, sincerity, and genuineness. Apparent sincerity makes people seem honest and forthright, which is a key to successful influence. Influence attempts will be successful when it is perceived by others that there are no concealed motives behind the behaviour exhibited. Therefore, people high in apparent sincerity inspire trust and confidence because they do not appear to be manipulative or coercive $[5,16,17]$.

The last research variable, which is transformational leadership, is manifested in four characteristics. First, transformational leaders are charismatic. They communicate a vision and provide a sense of mission which guide and motivate followers. They instil pride and gain respect and trust from their followers. Second, they inspire their followers by communicating high expectations, using symbols to focus efforts, and expressing important purposes in simple ways. Third, transformational leaders promote intelligence, rationality, and careful problem solving. They are willing to take calculated risks to use innovative, sometimes unconventional strategies to achieve their goals. Fourth, transformational leaders facilitate and encourage the personal development of their followers. They consider each follower individually in coaching, giving feedback, and recognising achievements [11, 18].

In construction projects, project personnel need emotional intelligence to be self-aware, to manage their feelings and emotions, and to understand and manage the feelings and emotions of others. This understanding, i.e., emotional intelligence, is required to apply political skill when influencing other project stakeholders to do what needs to be done to ensure project success. Finally, these influence efforts are the prerequisite for project personnel in using transformational leadership to lead their staff to achieve key project objectives. The theoretical model, as illustrated in Figure 1, shows the hypothetical relationships between these research variables. Emotional intelligence is the initiator signifying that project personnel should start inwardly by understanding and managing emotions (both self and others). Then emotional intelligence is manifested in 


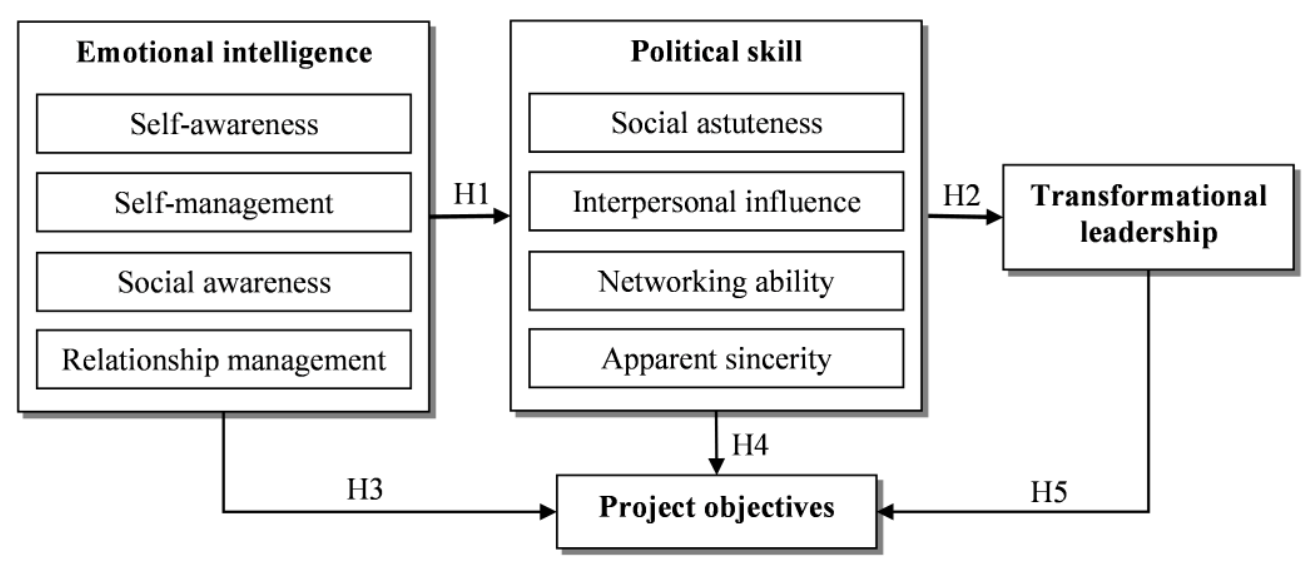

Figure 1. Theoretical Model and Hypotheses

the form of effective influence efforts through the application of political skill. Political skill also allows project personnel to become transformational leaders who generate superior performance from their teams. These three capabilities should promote the achievement of project objectives.

\section{Research Method}

Quantitative questionnaire survey was the research method chosen to test the hypotheses because the main aim of this research is theory testing to determine the degree of relationships among measured variables. The questionnaire was divided into three sections to measure the three constructs incorporated in this research. All questionnaires are self-assessed and use a Likert scale response format. The first section is the 28-item Emotional Intelligence Appraisal which has been validated across industries and job positions. It was designed to assess the four dimensions of emotional intelligence mentioned earlier [19]. The second section of the questionnaire is the 18-item Political Skill Inventory (PSI), which was designed to measure the four dimensions of political skill. PSI has undergone thorough processes to ensure its reliability and validity [5, 16]. The third section is the Global Transformational Leadership (GTL) scale, which contains seven items. The GTL has been tested in Australia with satisfactory reliability and validity to measure transformational leadership [18].

An additional section containing three items was included in the questionnaire to gather respondents' perceptions regarding the performance of their project in terms of time, cost, and quality aspects. These items were used to measure the achievement of project objectives in this research.

A number of construction organisations based in Sydney, Australia, were approached to participate in the survey which was conducted throughout the year of 2010. Three organisations (each has more than 300 staff) agreed to participate in the survey. Before data collection was carried out, meetings between the researchers and safety and senior managers of the participating organisations were held. The questionnaire was then distributed through a web-based online survey. All project personnel who were working on ongoing projects during the time of the survey were invited to participate in the survey. The managers of the participating organisations provided valuable supports by distributing the online survey links to their colleagues and subordinates. In addition, reminding emails were sent periodically by the managers and researchers to encourage more responses.

The hypotheses were tested using structural equation modelling (SEM), a statistical method that takes a hypothesis-testing approach to the analysis of a structural theory bearing on some phenomenon [20]. This method allows a simultaneous examination of relationships among independent and dependent variables or constructs within a theoretical model [21]. The basic steps of SEM include: specifying a model based on theory, determining how to measure constructs, collecting data, and analysing data which include overall model fit statistics and parameter estimates [22]. AMOS 18 (analysis of moment structures version 18) was the SEM software packages used in this research. Other statistical analyses were conducted using PASW Statistics 18.

\section{Analysis and Results}

In total, 353 respondents participated in which 273 questionnaires were completed properly and can be used for further analysis. Various project personnel have participated in the survey ranging from safety personnel, site supervisors, engineers, project mana- 
gers, and construction managers. Ninety-three percent of the respondents were male $(\mathrm{N}=255)$ and seven percent of the respondents were female $(\mathrm{N}=18)$. Most of the respondents were experienced people in the construction industry with the average work experience of more than 18 years.

Whilst maintaining the theoretical model, some modifications were made to obtain superior goodness of fit. The best-fit model is shown in Figure 2 and the fit indices of the model are listed in Table 1 . Hu and Bentler [23] recommended a two-index presentation strategy to indicate a good model fit. They suggested that the CFI should be 0.96 or higher and the RMR is 0.09 or lower. These requirements are met by the final model.

In Figure 2, the numbers on the arrows are the path coefficients or unstandardised regression weights (ranging from 0 to 1). An unstandardised regression coefficient represents the amount of change in dependent variable per single unit change in the predictor variable. For example, for every single unit of increase in self-awareness, the level of self-management is increased by 0.49 . All path coefficients are

Table 1. Fit indices

\begin{tabular}{cccccccc}
\hline $\begin{array}{c}\text { Chi- } \\
\text { Square }\end{array}$ & RMSEA & GFI & AGFI & RMR & NFI & TLI & CFI \\
\hline $\begin{array}{c}94.576 \\
\text { Dof }=44\end{array}$ & 0.065 & 0.950 & 0.911 & 0.029 & 0.932 & 0.943 & 0.962 \\
$p=0.000$ & & & & & & & \\
\hline
\end{tabular}

statistically significant $(p<0.001)$ providing strong support for the hypothesised model [22].

\section{Discussion}

The final model generally supports the research hypotheses. It demonstrates that emotional intelligence promotes the application of political skill which in turn enabling project personnel to become transformational leaders. These relationships positively influence the achievement of project objectives comprising time, cost, and quality. However, the relationships are not as straightforward as hypothesised in the theoretical model which will be expounded further in the following subsections.

\section{The Interrelationship among the Emotional Intelligence Dimensions}

Based on the best-fit model, self-awareness is the prerequisite of the other three dimensions and the dimension that initiates all the relationships. Selfawareness is an ability that has been appreciated since the ancient times. Recent research has also found that people with high self-awareness understand their strengths and limitations, a competency prominent among best performing managers. People high in self-awareness seek feedback, learn from their mistakes, and understand when to work with others who have complementary strengths. This understanding of oneself brings about greater understanding of others, making them appear trustworthy

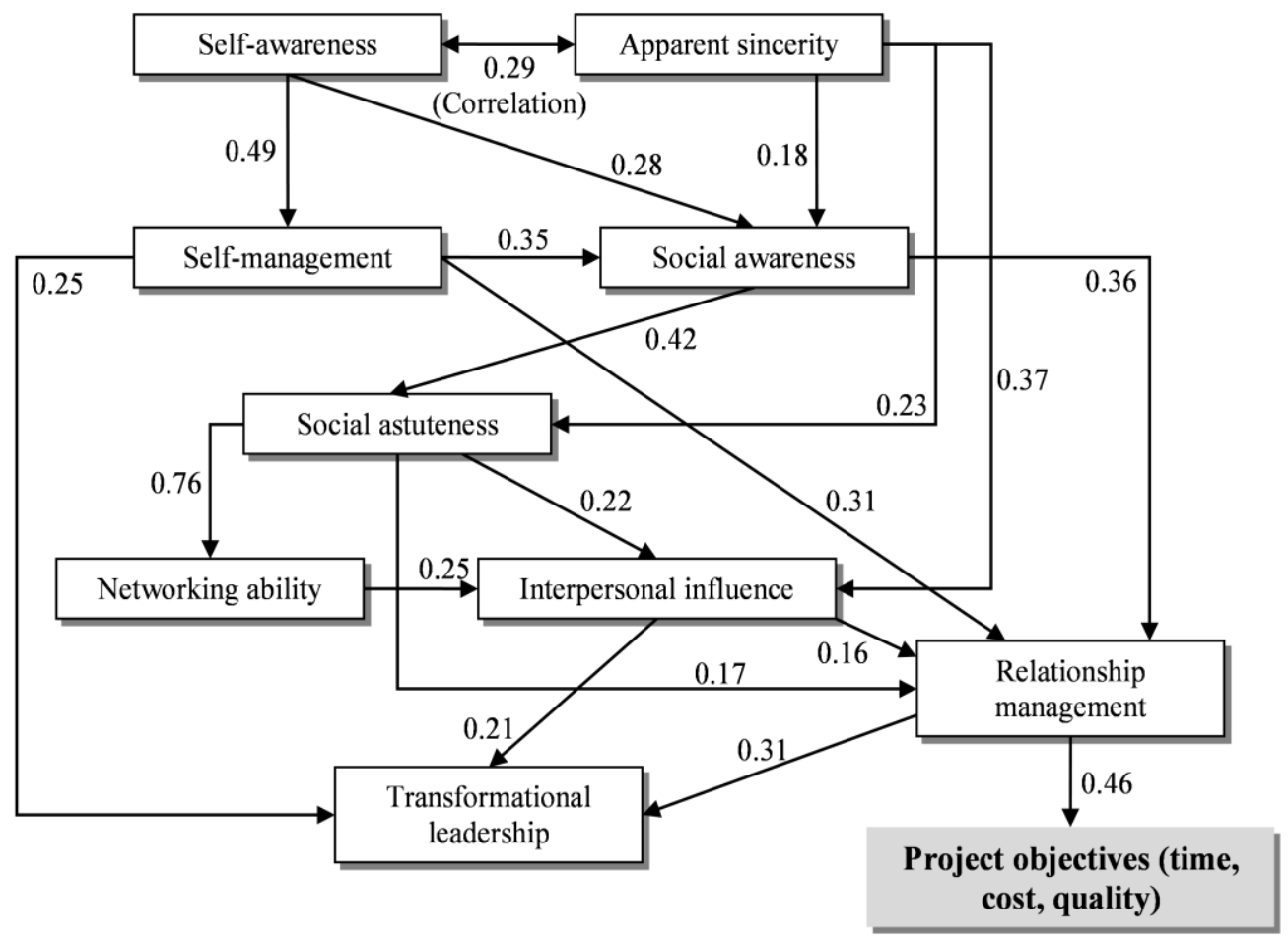

Figure 2. The Best-fit Model 
and competent [24]. Furthermore, self-awareness provides necessary information that forms the basis of self-reinforcement or goal establishment, which is the prerequisite of self-management [25]. All this results in the development of self-confidence, which is a significant predictor of performance [14]. The finding of this present research supports a proposition which says that self-awareness is the core and starting point of emotional intelligence [26, 27] as well as a key to succeed and work effectively with others [24].

Next, self-management is the predictor of social awareness and relationship management. The relationships are evident given that people who cannot control their emotional outbursts will have less chance to be effective in understanding others and developing relationships [14]. At neurological level, it was also found that self-management is the foundation of social effectiveness [28]. Lastly, social awareness is a predictor of relationship management. Understanding of own emotions and the emotions of others is a way to create effective social interactions [29]. People with high social awareness understand different points of view, making them effective in their interactions with different types of people. It is easier for them to get along in organisational life, build networks, and employ influence tactics to achieve positive results [2]. This interrelationship among the dimensions of emotional intelligence corroborates a research study which found that relationship management depends on a foundation of self-management and social awareness, each of which in turn requires self-awareness [14].

\section{The Interrelationship among the Political Skill Dimensions}

Based on the model shown in Figure 2, apparent sincerity is the dimension of political skill that initiates all relationships. It is frequently said that first impressions are crucial in any relationships because they are lasting and influence the way people see subsequent data about the perceived object or person. Therefore, making favourable first impressions is important in every socialisation process [30], particularly in the construction project environment due to the involvement of various stakeholders who have different backgrounds and expectations.

The model also indicates that social astuteness is a very strong predictor of networking ability. Socially astute people are experts in social interactions and accurately interpret their own behaviour and those of others in social settings [16]. This understanding of others and how interpersonal interactions work within a construction project makes socially astute project personnel able to determine the right approach to build and maintain networks, with influential people, who can help them achieve personal and project goals.

The last set of relationships shows that social astuteness, networking ability, and apparent sincerity, are the prerequisites of interpersonal influence. People with high interpersonal influence are flexible and can appropriately adapt their behaviour to various situations to elicit the desired responses from others. Additionally, they are able to influence others to do certain things and behave fittingly, all of which allows for organisational goals to be attained [5, 7, 16]. In order to influence others, project personnel need to be self-aware, have a good understanding of others, and know how a construction project is managed by using their social astuteness. This helps project personnel analyse and employ the right influence tactics beneficial for the projects [31]. Apparent sincerity is the strongest predictor among the three, which shows that it is imperative for project personnel to appear genuine without any hidden agendas if they want to influence others to do something. They need to appear sincere and show that their sole intention is to achieve project success. This confirms the argument proposed by Ferris et al. [32], who claimed that apparent sincerity is the core that makes political skill work. Apparent sincerity allows people to exert influence in a way that does not create ill-will or undue influence, thus others do not question their motives nor react negatively. Lastly, by developing networks (through networking ability) it will be much easier to influence people who are already in the networks or to use those networks to influence others. People with high networking ability are often expert negotiators, deal makers, and at ease with conflict management [5]. These virtues are vital to influence and lead project stakeholders to reach accord, and attain project objectives.

These causal relationships align with a statement by Holden [10], who argued that people who practice influence have the following qualities: the ability to see from a big picture perspective (understand organisational objectives and strategies); having a clear insight on the role of different people to achieve objectives; the ability to align personal goals with others; and a non-threatening appearance. In this case, social astuteness is the key to seeing the whole picture of a construction project, understanding the roles of various stakeholders, and identifying social interactions and alliances within the project. Using networking ability, project personnel can develop relationships with others, thus finding common ground or alignment to work together and achieve project objectives. Lastly, non-threatening appearance 
is related to apparent sincerity where project personnel seem honest and forthright, without appearing manipulative and coercive.

\section{The Interrelationship between Emotional Intelligence and Political Skill}

It was hypothesised that project personnel use emotional intelligence to understand their own emotions and the emotions of others. This understanding leads to the effective application of political skill. However, the best-fit model derived from the SEM analysis shows that the relationship is much more complex than initially envisaged. It demonstrates that the dimensions of emotional intelligence and political skill work concurrently to develop and manage relationships with others. Self-awareness of emotional intelligence and apparent sincerity of political skill are the initiators. As discussed previously, without self-awareness, people will not be able to manage themselves, not to mention managing others. Apparent sincerity, on the other hand, is needed to create positive first impressions in dealing with others.

Thereafter, the model shows that social awareness is a predictor of social astuteness. Social awareness is the ability to understand the emotions of others. Similarly, socially astute people understand the behaviour of others and interpersonal interactions that take place in social settings. This makes the relationship between the two logical. Observing and understanding the emotions of others enables project personnel to understand the bigger picture concerning social situations and interpersonal interactions in the construction project environment. Such an ability to read others helps project personnel develop their social networks and enable them to adapt their behaviours to exercise a strong influence on other people. Finally, this understanding of people and effective application of influence tactics positively influences the ability of project personnel to manage social interactions successfully.

\section{The Development of Transformational Leader- ship and Achievement of Project Objectives}

There are three prerequisites of transformational leadership, namely, self-management, interpersonal influence, and relationship management. The relationship between self-management and transformational leadership is obvious. Individuals have to manage themselves first and control outbursts of emotions if they aspire to be effective leaders. Self-management can be considered as a form of self-leadership where people motivate themselves to achieve their goals. Without this self-leadership, it is impossible for them to convince and influence others to be their willing and inspired followers [2].
Transformational leaders are charismatic and have the ability to stimulate and inspire their followers to achieve extraordinary outcomes for the good of the organisation [11]. In this case, interpersonal influence is crucial to communicate visions that instil pride and to gain respect and trust from the project team. It is also valuable to employ a range of influence tactics to inspire and motivate team members to focus their efforts for achieving successful project outcomes.

The last relationship is between relationship management and transformational leadership. Goleman [14] suggested that people competent in relationship management are able to sense people's developmental needs, making them excellent coaches and mentors. They are influential and articulate a shared vision that arouses enthusiasm and inspires others to work together towards common goals. They are also change catalysts which bring greater efforts and better performance from their subordinates. It can be observed from here that relationship management generates competencies required by individuals to be transformational leaders.

The model, however, does not support the hypothesis which conceptualises the influence of transformational leadership in the achievement of project objectives. This lack of relationship may be due to the characteristics of the construction project environment. First, the durations of construction projects are relatively short, thus project personnel only have limited amount of time to build relationships with their team members, making it even harder for them to transform their followers through coaching and mentoring. It is also difficult to create an inspiring long-term vision which characterises effective transformational leaders when trade workers only focus on their own scope of work and leave the project immediately after their work is completed only to be replaced by other groups of workers. Second, stakeholders in construction projects come from different organisations, thus project personnel may not have direct control over most of them. Therefore, project personnel's influence to change these external stakeholders' mindset and behaviour is constrained.

The last association in the model shows that relationship management positively influences the achievement of project objectives. The application of the relationship management dimension is aimed at managing interactions successfully. It is a key to ensure clear communication and effective conflict resolution. Relationship management helps people develop solid relationships with others, thus giving people the skills to make the most out of every interaction [15]. These abilities are valuable in the construction project environment where project 
stakeholders are numerous and diverse. If stakeholders are not managed effectively, the probability of successful project completion is reduced due to conflicts between stakeholders. Ineffective stakeholder management can lead to dissatisfaction with project outcomes and adverse disruption to the achievement of project objectives. Project personnel, therefore, have to apply their relationship management skill to proactively reach out to stakeholders, actively create good relationships and mutual trust, and consistently keep stakeholders satisfactorily informed, involved, consulted, and collaborated with [33].

\section{Skill Development Prioritisation}

Project personnel should prioritise their skill development so they can effectively facilitate the achievement of project objectives in their projects. Figure 3 simplifies and suggests how project personnel should prioritise their skill development. Self-awareness, apparent sincerity, and self-management are the base skills, which involve only own self. They are the precursors of social awareness and social astuteness, which are the skills to observe and understand people. The next tier is skills to manage social interactions, which consist of networking ability, interpersonal influence, and relationship management. Finally, all these skills help project personnel to be transformational leaders and effectively manage the achievement of project objectives.

\section{Conclusion}

Research has confirmed the value of emotional intelligence, political skill, and transformational leadership in organisations. However, there is a lack of integration concerning research in these areas which may cause confusion for organisations and individuals to develop their skills.

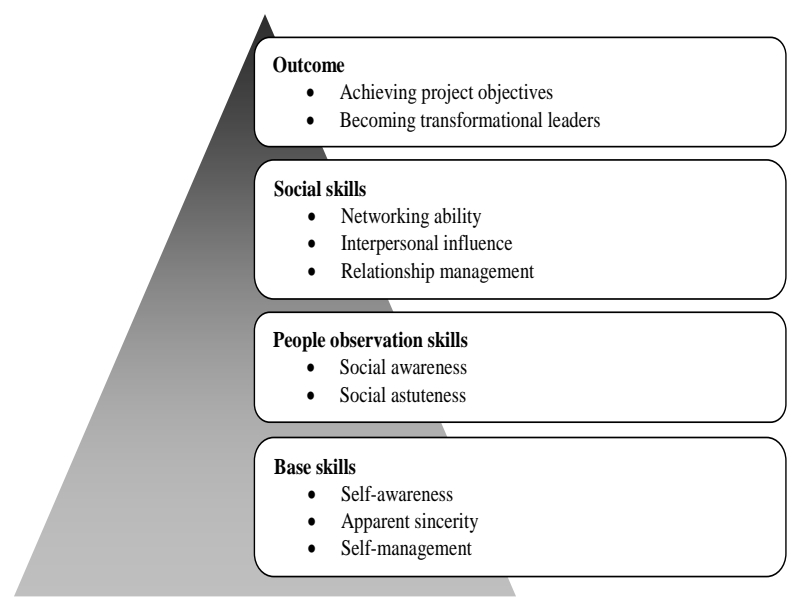

Figure 3. Construction Project Personnel's Skill Development Prioritisation
This research, therefore, has attempted to integrate the three skill constructs and show their interrelationship and influence in achieving organisational success, particularly in the construction project environment. By understanding this interrelationship, construction organisations and project personnel will be able to prioritise in their skill development process.

The research has found that the base skills that project personnel should prioritise first are selfawareness, apparent sincerity, and self-management. The next tier of skills that they need to develop is the ability to observe and understand people consisting of social awareness and social astuteness skills. Thereafter, project personnel can focus on their social skills, which include networking ability, interpersonal influence, and relationship management. By applying this skill development process, it is expected that project personnel will be able to improve their contribution in the achievement of project objectives and become transformational leaders.

Building on the findings of this research, future research should focus on how construction organisations and project personnel can develop the important skills identified in this research. For example, research may focus on developing effective training programs for project personnel to develop their skills. Furthermore, it is also important to measure the effectiveness of such training programs in practice and determine their impacts on the attainment of project and organisational objectives.

\section{References}

1. Goleman, D., Working with Emotional Intelligence, New York: Bantam Books, 1998.

2. Robbins, S.P. and Hunsaker, P.L., Training in Interpersonal Skills: TIPS for Managing People at Work, Upper Saddle River, NJ: Pearson Prentice Hall, 2009.

3. Sunindijo, R.Y., Hadikusumo, B.H.W. and Ogunlana, S., Emotional Intelligence and Leadership Styles in Construction Project Management. Journal of Management in Engineering, 23(4), 2007, pp. 166-170.

4. Sunindijo, R.Y. and Hadikusumo, B.H.W., Benefits of Emotional Intelligence to Project Management: A Study of Leadership and Conflict Resolution Style of Project Managers in Thailand. in The Queensland University of Technology Research Week International Conference, 2005, Brisbane, Australia: Queensland University of Technology. 
5. Ferris, G.R., et al., Political Skill at Work: Impact on Work Effectiveness, Mountain View, CA: Davies-Black Publishing, 2005.

6. Brouer, R.L., et al., The Moderating effect of Political Skill on the Demographic DissimilarityLeader-member Exchange Quality Relationship, The Leadership Quarterly, 20(2), 2009, pp. 61-69.

7. Ferris, G.R., et al., Political Skill at Work, Organizational Dynamics, 28(4), 2000, pp. 25-37.

8. Smith, A.D., et al., A Qualitative Study of HighReputation Plant Managers: Political skill and Successful Outcomes. Journal of Operations Management, 27(6), 2009, pp. 428-443.

9. Vigoda, E., Developments in Organizational Politics: How Political Dynamics Affect Employee Performance in Modern Worksites, Cheltenham, UK: Edward Edgar, 2003.

10. Holden, M., Positive Politics: Overcome Office Politics \& Fast-track Your Career, Warriewood, NSW, Australia: Business \& Professional Publishing, 1998.

11. Bass, B.M., From Transactional to Transformational Leadership: Learning to Share the Vision, Organizational Dynamics, 18(3), 1990, pp. 19-31.

12. Robbins, S.P., et al., Management. $5^{\text {th }}$ ed., Pearson Education Australia, 2009.

13. Prabhakar, G.P., Switch Leadership in Projects: An Empirical Study Reflecting the Importance of Transformational Leadership on Project Success Across Twenty-eight Nations, Project Management Journal, 36(4), 2005, pp. 53-60.

14. Goleman, D., An EI-based theory of Performance, in The Emotionally Intelligent Workplace, C. Cherniss and D. Goleman, Editors, Jossey-Bass: San Francisco, 2001, pp. 27-44.

15. Bradberry, T. and Greaves, J., Emotional Intelligence 2.0, San Diego, CA: TalentSmart, 2009.

16. Ferris, G.R., et al., Development and Validation of the Political Skill Inventory. Journal of Management, 31(1), 2005, pp. 126-152.

17. Ferris, G.R., et al., Political Skill in Organizations, Journal of Management, 33(3), 2007, pp. 290-320.

18. Carless, S.A., Wearing, A.J. and Mann, L., A Short Measure of Transformational Leadership, Journal of Business and Psychology, 14(3), 2000, pp. 389-405.

19. Bradberry, T. and Greaves, J., The Emotional Intelligence Appraisal-Me Edition: There is more than IQ. 2001-2010, San Diego: TalentSmart.

20. Byrne, B.M., Structural Equation Modeling with AMOS Basic Concepts, Applications, and Programming, $2^{\text {nd }}$ ed., New York: Routledge, 2010.
21. Mohamed, S., Safety Climate in Construction Site Environments. Journal of Construction Engineering and Management, 128(5), 2002, pp. 375-384.

22. University of Texas Structural Equation Modeling Using AMOS: An Introduction, 2002.

23. Hu, L.T. and Bentler, P.M., Cutoff Criteria for Fit Indexes in Covariance Structure Analysis: Conventional Criteria versus new Alternatives. Structural Equation Modeling, 6(1), 1999, pp. 155.

24. Janasz, S.D., et al., Interpersonal Skills in Organisations, Boston: McGraw-Hill, 2006.

25. Manz, C.C. and Sims Jr., H.P., Self-management as a Substitute for Leadership: A Social Learning Theory Perspective, Academy of Management Review, 5(3), 1980, pp. 361-367.

26. Jordan, P.J. and Ashkanasy, N.M., Emotional Intelligence, Emotional Self-awareness, and Team Effectiveness, in Linking Emotional Intelligence and Performance at Work: Current Research Evidence with Individuals and Groups, V.U. Druskat, F. Sala, and G. Mount, Editors, Lawrence Erlbaum Associates: New Jersey, 2006, pp. 145-163.

27. Mersino, A.C., Emotional Intelligence for Project Managers: The People Skills You Need to Achieve Outstanding Results, New York: AMACOM, 2007.

28. Damasio, A., Descartes' Error: Emotion, Reason, and the Human Brain, New York: Grosset/ Putnam, 1994.

29. Lane, R.D., Levels of Emotional Awareness: Neurological, Psychological, and Social Perspectives, in The Handbook of Emotional Intelligence, R. Bar-On and J.D.A. Parker, Editors, JosseyBass: San Francisco, 2000, pp. 171-191.

30. Chung, K.H. and Megginson, L.C., Organizational Behavior: Developing Managerial Skills, New York: Harper \& Row, 1981.

31. Buchanan, D. and Badham, R., Power, Politics, and Organizational Change: Winning the Turf Game, London: Sage Publications, 1999.

32. Ferris, G.R., Davidson, S.L. and Perrewé, P.L., Developing Political Skill at Work. Training, 42(11), 2005, pp. 40-45.

33. Manowong, E. and Ogunlana, S., Strategies and tactics for managing construction stakeholders, in Construction Stakeholder Management, E. Chinyio and P. Olomolaiye, Editors, WileyBlackwell: Hoboken, 2009, pp. 121-137. 